\title{
Avaliação da eficiência do método SODIS na desinfecção da água para consumo humano em Pelotas/RS
}

A água contaminada por microrganismos patogênicos é a causadora de diversas doenças de veiculação hídrica, portanto a sua desinfeção se faz necessária. 0 SODIS é um método barato e simples de desinfecção da água por meio da radiação solar, podendo ser aplicado em comunidades menos favorecidas em infraestrutura e recursos financeiros. O presente trabalho buscou aplicar no município de Pelotas o método SODIS com diferentes tempos de exposição para dias nublados e ensolarados, a fim de determinar o tempo ótimo de exposição para as respectivas condições climáticas. As amostras de água bruta com turbidez menor que 30 NTU, foram expostas à radiação solar em garrafas PET transparentes por um período 6,7 e 8 horas em dias ensolarados, e por 8 , 29 e 32 horas em dias nublados. Após os respectivos tempos de exposição, as amostras de água tiveram suas cargas microbiológicas analisadas pelos parâmetros de Coliformes Totais, Escherichia coli e Coliformes Termotolerates. Os resultados obtidos foram satisfatórios, o método apresentou $100 \%$ de eficiência de inativação dos microrganismos analisados, em dias ensolarados a carga microbiológica se mostrou ausente em 8 horas de exposição à energia solar, já em dias nublados o tempo foi de 32 horas, sendo estes os tempos ótimos de exposição à radiação solar para cada condição climática.

Palavras-chave: SODIS; Desinfecção Solar; Tratamento de Água; Água Potável.

\section{Evaluation of the efficiency of the SODIS method in the disinfection of water for human consumption in Pelotas/RS}

The contaminated by pathogenic microorganism water causes several waterborne diseases, so its disinfection therefore is necessary. SODIS is a cheap and simple water disinfection method that uses solar radiation, and it can be applied in disadvantaged communities. The present work aimed to apply SODIS with different exposure times both on cloudy and sunny days in order to ascertain the best time of exposure in each weather condition. Raw water samples with turbidity lower than 30 NTU were exposed to solar radiation in PET transparent bottles for 6,7 and 8 hours on sunny days, and for 8,29 and 32 hours on cloudy days. After every exposure time, the microbiological quality of the water samples was analyzed concerning total coliforms, Escherichia coli and fecal coliforms. The work's results were satisfactory and the method had $100 \%$ efficiency concerning the analyzed microorganisms' inactivation. On sunny days the suitable disinfection level occur in 8 hours of solar energy exposure whereas on cloudy days that time was 32 hours, being these the best exposure time in each weather condition.

Keywords: SODIS; Solar Disinfection; Water Treatment; Drinking Water.

Topic: Engenharia Ambiental

Reviewed anonymously in the process of blind peer.
Received: $10 / 08 / 2018$

Approved: 24/09/2018
Bruno Müller Vieira

Universidade Federal de Pelotas, Brasil

http://lattes.cnpq.br/1885554662703620

bruno.prppg@hotmail.com

Natália Golin

Universidade Federal de Pelotas, Brasil

http://lattes.cnpq.br/1885554662703620

nataliagolin.esa@hotmail.com

Marlon Heitor Kunst Valentini

Universidade Federal de Pelotas, Brasil

http://lattes.cnpq.br/6499660114940771

marlon.valentini@hotmail.com

\author{
Marília Guidotti Corrêa (D) \\ Universidade Federal de Pelotas, Brasil \\ http://lattes.cnpq.br/2113299633932476 \\ http://orcid.org/0000-0001-9091-6001 \\ mariliaguidotti@yahoo.com.br \\ Francine Vicentini Viana \\ Universidade Federal de Pelotas, Brasil \\ http://lattes.cnpq.br/0219375029813785 \\ fravivi@gmail.com \\ Willian Cézar Nadaleti \\ Universidade Federal de Pelotas, Brasil \\ http://lattes.cnpq.br/4670559561277136 \\ http://orcid.org/0000-0002-4727-4127 \\ williancezarnadaletti@gmail.com
}

Referencing this:

VIEIRA, B. M.; GOLIN, N. VALENTINI, M. H. K.; CORRÊA, M. G.; VIANA, F. V.; NADALETI, W. C.. Avaliação da eficiência do método SODIS na desinfecção da água para consumo humano em Pelotas/RS. Revista Ibero Americana de Ciências Ambientais, v.9, n.7, p.158-170, 2018. DOI: http://doi.org/10.6008/CBPC2179-6858.2018.007.0015

DOI: 10.6008/CBPC2179-6858.2018.007.0015 


\section{INTRODUÇÃO}

Água em quantidade suficiente e de boa qualidade é essencial para a vida, porém, conforme apresentado no relatório da Organização Mundial da Saúde - OMS e do Fundo das Nações Unidas para a Infância - UNICEF (WHO et al., 2017), cerca de três em cada dez pessoas não têm acesso a água potável em casa. Ou seja, mais de 2 bilhões de pessoas não possuem água gerenciada de forma segura, e destas, 159 milhões consomem água não tratada que provém de fontes superficiais, como córregos ou lagos. No Brasil, dos 57.324 .167 domicílios, 47.494 .025 (82,85\%.) estão ligados a rede geral de abastecimento de água, ou seja, cerca de 9.830 .142 residências ainda não possuem acesso a rede geral (IBGE, 2010). Devido ao rápido crescimento da população mundial, é esperado que a demanda por água cresça em quase um terço até 2050 (ONU, 2018).

A Qualidade da Água está relacionada com suas características mensuráveis de natureza física, química e biológica. Tais características quando mantidas dentro de limites estabelecidos, viabilizam o uso da água para determinado fins. Estes limites constituem os critérios, normas e padrões legais para o uso da água (SOUZA, 2005). Existem diversos padrões mundiais, dos quais os mais conhecidos são: Padrão Internacional da Organização Mundial da Saúde (OMS), o qual é o guia da maioria dos outros padrões nacionais; Padrão Americano - United States 19 Environmental ProtectionAgency (USEPA) e Padrão da Comunidade Europeia (80/778/EEC). No Brasil, estes Padrões são definidos pela Portaria MS no 2.914 de 12 de Dezembro de 2011 do Ministério da Saúde (TELLES et al., 2007).

Conforme a Portaria MS no 2.914 a definição de água potável é: “Água para consumo humano cujos parâmetros microbiológicos, físicos, químicos e radioativos atendam ao padrão e não ofereçam riscos à saúde". Essa Portaria, além de dispor sobre o padrão de potabilidade da água para consumo humano, também dispõe sobre os procedimentos de controle e vigilância da qualidade da mesma. Conforme consta no Capítulo 4 do seu anexo, a água para consumo humano, no que se refere a microrganismos, deve conter ausência de Coliformes totais e de E. coli em $100 \mathrm{ml}$ de amostra.

O consumo de água de boa qualidade é extremamente importante para manter a sadia qualidade de vida da população, protegendo contra doenças de veiculação hídrica. Tais doenças são ocasionadas majoritariamente por microrganismos patogênicos de origem entérica, os quais são excretados nas fezes humanas ou animais e posteriormente são ingeridos pelo consumo da água ou alimento contaminado com as fezes (GRABOW, 1996).

O objetivo da desinfecção da água é destruir os microrganismos patogênicos e também os microrganismos indicadores presentes na água. A desinfecção é uma das etapas do tratamento de potabilização da água e é feitas por agentes físicos e químicos (LIBÂNO, 2016). Os agentes químicos são compostos ou elementos que tem potencial de oxidação, sendo que os mais utilizados são cloro e seus compostos, dióxido de cloro e ozônio. Já os agentes físicos estão relacionados à energia da radiação, sendo os principais a radiação ultravioleta, radiação solar e à fervura (OLIVEIRA, 2014). 
Desde os anos 90, a poluição das águas vem piorando em quase todos os rios da América Latina, África e Ásia. Estudos informam que a qualidade da água irá se deteriorar ainda mais nas próximas décadas, o que aumentará ameaças à saúde humana, ao meio ambiente e ao desenvolvimento sustentável. Globalmente, o maior problema relacionado à qualidade da água é a carga de nutrientes a qual é frequentemente associada carga de patógenos (ONU, 2018). Muitas vezes faltam dados específicos sobre o alcance da poluição e degradação da qualidade da água, o que amplifica ainda mais os desafios relacionados à gestão da qualidade da água (UN-WATER, 2016).

A degradação da qualidade da água é refletida diretamente sobre riscos ambientais, sociais e econômicos, que afetam a saúde humana, limitam a produção de alimentos, reduzem a funcionalidade dos ecossistemas e impedem o crescimento econômico (UNESCO, 2015). Portanto, a qualidade da água é fundamental para o conceito de desenvolvimento sustentável, que vem sendo buscado através da Agenda 2030 para Desenvolvimento Sustentável, que tem por objetivo assegurar a disponibilidade e gestão sustentável da água e saneamento para todas e todos.

Tratando-se do estado do Rio Grande do Sul, conforme dados do IBGE, o número estimado de habitantes é de 11.322.895. Dos 3.599.604 domicílios do RS, 3.071 .715 (85,33\%) estão ligados a rede de distribuição de água. Entre os 496 municípios do estado, 178 apresentam percentuais de atendimento igual ou superior a do Estado (IBGE, 2010). Mesmo que as porcentagens pareçam elevadas, cerca de 527.889 residências ainda não possuem acesso à rede geral de distribuição de água.

No que concerne ao município do Pelotas, especificamente, dados apresentados pelo IBGE (2010) demonstram que a população é de aproximadamente 328.275 habitantes, com um total de 113.951 domicílios, destes, apenas 107.225 estão ligados com a rede de abastecimento municipal de água, ou seja, 5,9\% dos domicílios ainda não são atendidos por este serviço, situação que os faz buscar por outras alternativas de abastecimento, sendo elas: poço ou nascente na propriedade: 4.648 domicílios; poço ou nascente fora da propriedade: 1.350 domicílios; água da chuva armazenada em cisterna: 10 domicílios; água da chuva armazenada de outra forma: 5 domicílios; carro-pipa: 18 domicílios; rio, açude, lago ou igarapé: 15 domicílios; outra forma alternativa de abastecimento: 680 domicílios. Quanto aos casos de doenças que podem ser relacionadas à água na cidade, cerca de $0,01 \%$ da população de Pelotas é internada devido a casos de diarreia (IBGE, 2018).

A importância dos serviços de abastecimento público de água está intimamente ligada à prevenção das doenças de veiculação hídrica e à redução das taxas de mortalidade relacionadas ao consumo de água não potável. Porém, implantar Estações de Tratamento de Água (ETA) e sistemas que atendam a toda população é bastante complexo e caro, tornando o fornecimento de água tratada inexistente e precário em muitas localidades. Por este motivo, a população que não é atendida por estes serviços busca soluções alternativas de abastecimento de água, que incluem a captação de água em poços, nascentes, coleta de água pluvial, entre outras (OLIVEIRA, 2014).Por não receberem um tratamento dentro de normas definidas por órgãos de vigilância sanitária ou de saúde, as soluções alternativas de abastecimento de água são mais 
passíveis à contaminação que os sistemas de abastecimento público de água, apresentando maior risco à saúde humana (BRASIL, 2016).

Tal fato torna evidente a importância de opções alternativas acessíveis e eficientes para tratar a água destas localidades. Uma opção seria a desinfecção da água utilizando a energia solar, este método é conhecido como SODIS (Solar Water Desinfection). O procedimento basicamente consiste em armazenar a água a ser tratada em garrafas de Polietileno tereftalato (PET) transparentes e expô-las à radiação solar por um determinado período de tempo, até que seja feita a inativação dos microrganismos patogênicos (OLIVEIRA, 2014).

A eficiência do processo do SODIS tem grande relação com a quantidade de luz solar disponível. A radiação solar é distribuída de modo desigual por todo o mundo e varia em intensidade de um local geográfico para outro dependendo da estação, latitude e do tempo do dia. As regiões mais adequadas ao SODIS ficam situadas entre a latitude $15^{\circ} \mathrm{N}$ e $35^{\circ} \mathrm{N}$ e $15^{\circ} \mathrm{S}$ e $35^{\circ} \mathrm{S}$. A segunda região mais favorável situa-se entre o equador e latitude $15^{\circ} \mathrm{N}$ e $15^{\circ} \mathrm{S}$ (EAWAG, 2002). A luz solar emite radiações solares ultravioleta e infravermelha, processo que inativa microrganismos, tornando-se uma alternativa de desinfeção da água (OLIVEIRA, 2014).

Ainda no que concerne a eficiência do processo, de acordo com Sommer (1997), as partículas que ficam suspensas na água diminuem a penetração de radiação solar e protegem os microrganismos de serem irradiados, tornando o SODIS menos eficiente. O método requer água relativamente clara, com turbidez menor que 30 NTU (Unidade de Turvação Nephelometrica). Se a turvação da água for maior que 30 NTU, esta precisará de um pré-tratamento antes 25 de ser exposta.

A radiação UV-A sofre variações diárias e sazonais. A variação sazonal depende da latitude e é responsável pelo clima da região. Antes da implementação do SODIS em um local é necessário verificar as intensidades sazonais de radiação. Para que o SODIS tenha a eficiência adequada, é necessária uma intensidade de radiação solar total de pelo menos $500 \mathrm{~W} / \mathrm{m}^{2}$ durante aproximadamente 6 horas. Como a intensidade de radiação solar também está sujeita a variações diárias, com tempo nublado, menos energia de radiação está disponível, portanto durante estes dias a intensidade da radiação UV-A é reduzida a um terço da intensidade registrada durante um dia sem nuvens. Sendo assim, as garrafas com água do SODIS devem ser expostas durante dois dias consecutivos para alcançarem a dose de radiação exigida e assegurar a inativação completa do agente patogênico (SOMMER, 1997).

A primeira pesquisa sobre o método SODIS foi iniciada por Aftin Acra na Universidade Americana de Beirute, e posteriormente foi aprimorada pelo instituto EAWAG, na Suíça. Estas pesquisas verificaram a eficiência do método, e também a aceitação sociocultural do mesmo, obtendo um índice de aprovação de 84\% (EAWAG, 2002). Sua utilização em regiões menos favorecidas em infraestrutura e recursos financeiros é viável, pois a desinfecção é realizada através dos raios solares, uma fonte natural e disponível a todos, não há necessidade da dosagem de produtos químicos e pode ser realizada por meio da utilização de garrafas PET, que é um material descartado comercialmente. 
Devido à grande disponibilidade de garrafas tipo PET nos produtos de países de baixa e média renda, o método SODIS foi especificamente projetado e testado para este tipo de recipiente. Recomendam-se garrafas com volume máximo de 2 L, com uma profundidade de penetração máxima de $10 \mathrm{~cm}$. Recipientes com materiais que não sejam tipo PET podem ser usados na desinfecção solar, desde que tenham alta transmitância de radiação UV e não liberem para água substâncias potencialmente tóxicas (EAWAG, 2016).

Para avaliar a eficiência do SODIS na remoção de patógenos da água, é necessário que sejam feitas análises de indicadores que realmente possam comprovar esta eficiência. Alguns microrganismos patogênicos podem ser detectados de maneira direta, porém, requerem métodos analíticos caros e complicados. Por este motivo, ao invés de avaliar diretamente os agentes patogênicos, são utilizados organismos indicadores da poluição fecal da água. Para selecionar estes organismos indicadores, eles devem obedecer certos critérios, sendo eles: estar presente em número alto nas fezes humanas, ser detectável através de métodos simples, não se desenvolver em águas naturais, ser persistente na água e poder ser removido pelo método de tratamento de água semelhante ao agente patogênico transmitido através da água. Muitos destes critérios são preenchidos pelos Coliformes Termotolerantes e pela Escherichia coli, os quais são bons indicadores para avaliar a contaminação por fezes da água (WHO, 2011).

Sendo assim, esse trabalho objetiva avaliar a eficiência do método SODIS na desinfecção da água para consumo humano no município de Pelotas - RS, bem como realizar o experimento do SODIS para diferentes tempos de exposição em dias ensolarados e dias nublados e determinar o tempo ótimo de exposição da água ao sol pelo método SODIS para o município de Pelotas em dias nublados e em dias ensolarados.

\section{METODOLOGIA}

\section{Região de Estudo}

Pelotas está localizado à $31^{\circ} 37^{\prime}$ de Latitude Sul e $52^{\circ} 07^{\prime}$ de Longitude Oeste, estando a uma altitude de $3 \mathrm{~m}$, possuindo uma insolação total anual de 2328 horas e uma média anual de radiação solar de 132 W/m2 (WREGE, 2012). As amostras de água utilizadas no presente estudo foram coletadas na Estação de Tratamento de Água da Universidade Federal de Pelotas, Campus Capão do Leão, antes de passar pela etapa de tratamento, chamada de água bruta. A água que chega a ETA provém do Arroio Padre Doutor.

A área experimental selecionada para exposição das amostras à radiação solar está localizada na Agência de Desenvolvimento da Lagoa Mirim, da Universidade Federal de Pelotas. A área foi escolhida por não ter vegetação de grande porte nem edificações que sombreiam o experimento. As análises da água foram realizadas no Laboratório de Águas e Efluentes da própria agência.

\section{Instalação experimental}

Para serem expostas ao sol, as amostras de água foram acondicionadas em garrafas PET tipo 1, transparentes, com um volume de $2 \mathrm{~L}$, provenientes do uso para refrigerantes. Conforme apresentado na 
figura 1, as garrafas ficaram expostas à radiação solar na superfície de um telhado inclinado com telha ondulada de Amianto.

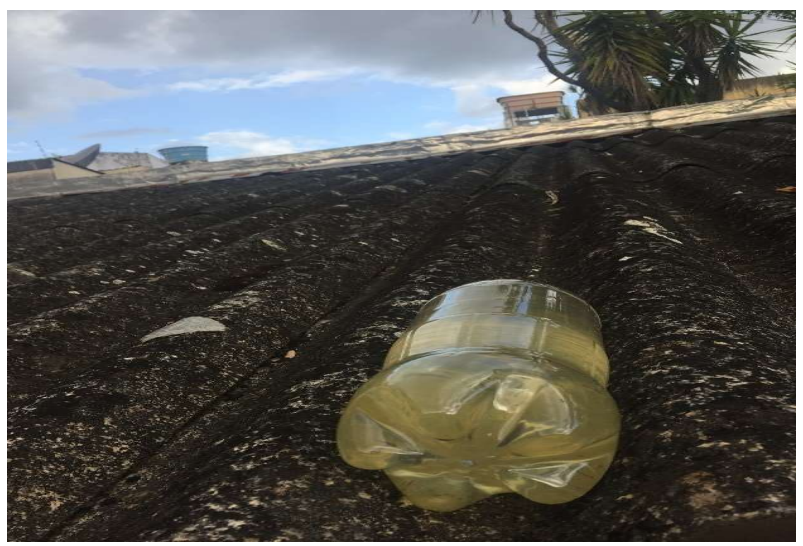

Figura 1: Garrafa exposta a radiação solar.

\section{Experimento}

As amostras de águas submetidas à desinfecção pelo método SODIS eram coletadas com um galão na ETA e se apresentavam com turbidez abaixo de 30 NTU eram armazenadas no refrigerador até o dia de serem expostas ao sol. Para iniciar os experimentos a água armazenada era previamente retirada do refrigerador para que ficasse em temperatura ambiente. Após este período era feita a homogeneização da água por meio da agitação do galão e posteriormente ela era distribuída em 4 garrafas previamente higienizadas, denominadas T0, T1, T2, T3. Foram realizadas 3 baterias de ensaios em diferentes dias ensolarados e 3 baterias em diferentes dias nublados, para que assim pudesse ser determinado o melhor tempo de exposição para cada condição climática. As etapas de condução do experimento estão apresentadas na figura 2 .

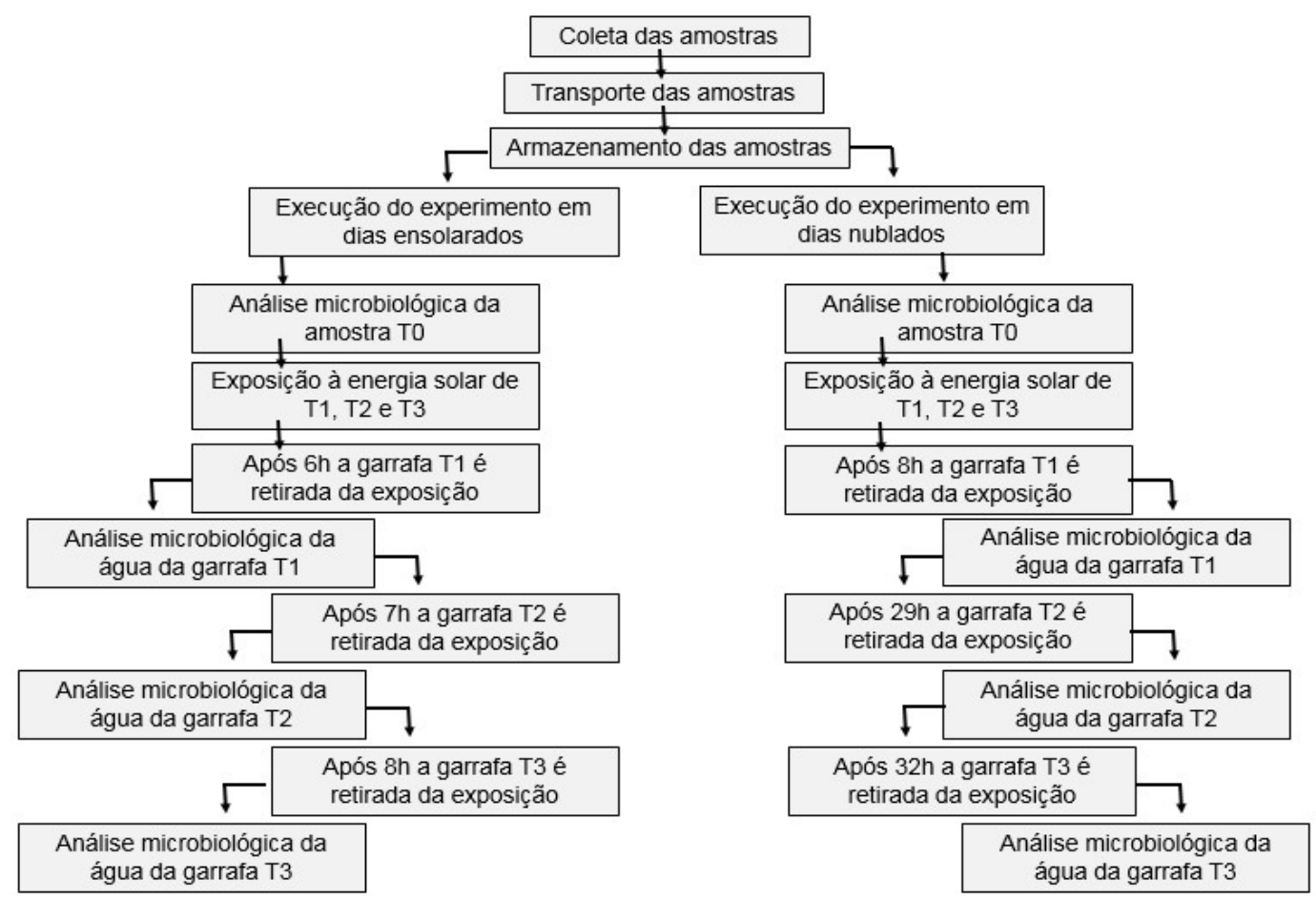

Figura 2: Etapas do experimento. 


\section{Experimento em dias ensolarados}

Os experimentos em dias ensolarados foram realizados nos dias 15 de fevereiro, 05 de abril e 09 de abril de 2018. A garrafa T0 era instantaneamente analisada, não sendo exposta à radiação solar, afim de analisar as condições microbiológicas iniciais da água, antes da mesma ser submetida à desinfecção solar. As garrafas T1, T2 e T3 foram expostas ao sol por 6h, 7h e 8h respectivamente, entre as 9:00 e 17:00 horas. Após o término do período de tempo determinado, a garrafa era retirada do sol e a análise para avaliar as condições microbiológicas da água era feita imediatamente.

\section{Experimento em dias nublados}

Os experimentos em dias nublados foram realizados nos dias 20 de fevereiro, 21 de fevereiro e 27 de fevereiro de 2018. A garrafa T0 não era submetida ao SODIS e sua água era instantaneamente analisada, para verificar as condições microbiológicas iniciais da água, antes da mesma ser submetida à desinfecção solar. Devido a redução da passagem da radiação UV-A em dias nublados, as garrafas ficaram expostas à radiação solar por mais tempo. Sendo o tempo de exposição de T1 de 8h, T2 de $29 \mathrm{~h}$ e T3 de 32h. Após cada período de tempo, a respectiva garrafa era retirada do sol e a análise microbiológica da água era feita.

\section{Análises Microbiológicas}

Adotou-se uma metodologia de análises microbiológicas das amostras conforme 'Standard Methods for the Examinationof Water and Wastewater' (APHA, 2017), sendo o método de tubos múltiplos o utilizado para determinação de Coliformes Totais, Coliformes Termotolerantes e Escherichia coli, essas analises seguiram os procedimentos conforme APHA (2017). Por meio deste método é quantificado nas amostras de água o Número mais Provável (NMP) dos microrganismos citados.

\section{Eficiência de inativação dos microrganismos}

Para verificar a eficiência de inativação de microrganismos dos diferentes tempos de exposição, é utilizada a Equação (1), conforme apresentada

$$
E=\frac{\text { NMPfinal-NMPinicia }}{\text { NMPinicial }} X 100
$$

Onde a eficiência de ativação de microrganismos é dada em porcentagem e representada pela letra 'E', NMPfinal é número mais provável das amostras em TO e NMPinicial é o número mais provável das amostras nos tempos analisados (T1, T2 ou T3)

\section{RESULTADOS E DISCUSSÃO}

O local de realização do experimento foi no município de Pelotas que está localizado à $31^{\circ} 37^{\prime}$ de Latitude Sul, possuindo uma insolação total anual de 2328 horas e uma média anual de radiação solar de 132 
W/m2 (WREGE, 2012). Assim sendo, o local está entre latitude de $15^{\circ} \mathrm{S}$ e $35^{\circ} \mathrm{S}$, onde ficam as regiões mais adequadas para aplicação do SODIS (EAWAG, 2002).

As condições experimentais, relacionadas ao clima, foram determinadas pela predominância ou não de nuvens no céu. Pois, segundo Sommer (1997), em dias com tempo nublado, menos energia de radiação está disponível, e nestes dias as garrafas com água do SODIS devem ser expostas durante dois dias consecutivos para alcançarem a dose de radiação exigida e assegurar a inativação completa do agente patogênico. Já em dias ensolarados, para que o SODIS tenha a eficiência adequada, é necessária uma intensidade de radiação solar total de pelo menos $500 \mathrm{~W} / \mathrm{m}^{2}$ durante aproximadamente 6 horas. Devido ao fato de Pelotas possuir uma média radiação solar de $132 \mathrm{~W} / \mathrm{m} 2$, a qual é menor que a recomendada, o tempo de exposição variou de 6 à 8 horas. A tabela 1 apresenta os dados meteorológicos de Pelotas nos dias em que foram realizados os experimentos do método SODIS.

Tabela 1: Dados Meteorológicos em Pelotas nos dias dos experimentos.

\begin{tabular}{|l|l|l|l|l|}
\hline Data & Condição Climática & Temperatura média $\left({ }^{\circ} \mathrm{C}\right)$ & Umidade Relativa $(\%)$ & Radiação Solar $\left(\mathrm{W} / \mathrm{m}^{2}\right)$ \\
\hline $15 / \mathrm{fev}$ & Ensolarado & 21,3 & 77,8 & 330,19 \\
\hline $20 / \mathrm{fev}$ & Nublado & 23,9 & 88,3 & 120,04 \\
\hline $21 / \mathrm{fev}$ & Nublado & 23,3 & 86 & 212,48 \\
\hline $27 / \mathrm{fev}$ & Nublado & 20,9 & 88,3 & 175,91 \\
\hline $05 / \mathrm{abr}$ & Ensolarado & 20,5 & 85,1 & 209,04 \\
\hline $09 / \mathrm{abr}$ & Ensolarado & 22,8 & 88,7 & 177,75 \\
\hline
\end{tabular}

Fonte: EMBRAPA (2018).

Conforme apresentado por Borde (2016) a turbidez é um fator que varia muito em fontes de água de região para região. Água altamente turva reduz a eficiência da desinfecção solar, diminuindo a penetração da luz do sol através da água protegendo assim os micróbios da inativação. Como pode ser verificado na tabela 2, todas as amostras de água utilizadas no experimento apresentaram valores de Turbidez abaixo de $30 \mathrm{NTU}$, indicando que as mesmas estavam adequadas para serem submetidas ao método SODIS, conforme o SODIS Manual (EAWAG, 2016).

Tabela 2: Dados de turbidez das amostras de águas.

\begin{tabular}{|l|l|l|}
\hline Data & Amostra & Turbidez (NTU) \\
\hline $15 / \mathrm{fev}$ & T0 & 19,2 \\
\hline $20 / \mathrm{fev}$ & T0 & 19,2 \\
\hline $21 / \mathrm{fev}$ & T0 & 14,7 \\
\hline $27 / \mathrm{fev}$ & T0 & 18,4 \\
\hline $05 / \mathrm{abr}$ & T0 & 17,8 \\
\hline $09 / \mathrm{abr}$ & T0 & 22,7 \\
\hline
\end{tabular}

Por meio das análises microbiológicas foi quantificado o Número Mais Provável (NMP) dos microrganismos eliminados durante a aplicação do SODIS, com limite de confiança de $95 \%$, os resultados destas estão quantificados na tabela 3 e 6.

\section{Resultados em dias ensolarados}

Foram realizadas três baterias de ensaios em três diferentes dias ensolarados, afim de contrabalancear as variações climáticas existentes em diferentes dias. Os dias de ensaios selecionados aleatoriamente entre dias com presença predominante de sol, foram 15 de fevereiro, 05 e 09 de abril de 
2018. Os resultados das análises de água submetidas a Desinfeção Solar (SODIS), assim como da amostra de água bruta, são expressos em NMP de microrganismos por $100 \mathrm{~mL}$ de amostra de água e estão apresentados na tabela 3.

Tabela 3: NMP em $100 \mathrm{~mL}$ do experimento SODIS em dias Ensolarados.

\begin{tabular}{|c|c|c|c|c|c|}
\hline Amostra & Data & Tempo de Exposição (h) & Coliformes Totais & Coliformes Termotolerantes & E. coli \\
\hline TO & \multirow{4}{*}{$15 /$ fev } & 0 & 70 & 130 & 1,8 \\
\hline T1 & & 6 & 9,3 & Ausente & Ausente \\
\hline T2 & & 7 & 7,8 & Ausente & Ausente \\
\hline T3 & & 8 & Ausente & Ausente & Ausente \\
\hline TO & \multirow{4}{*}{ 05/abr } & 0 & 920 & 22 & 3,6 \\
\hline T1 & & 6 & 47 & 11 & Ausente \\
\hline T2 & & 7 & 6,1 & Ausente & Ausente \\
\hline T3 & & 8 & Ausente & Ausente & Ausente \\
\hline TO & \multirow{4}{*}{ 09/abr } & 0 & 17 & 4,5 & 1,8 \\
\hline T1 & & 6 & 4 & Ausente & 1,8 \\
\hline 2 & & 7 & 1,8 & Ausente & 1,8 \\
\hline T3 & & 8 & Ausente & Ausente & Ausente \\
\hline
\end{tabular}

As amostras T0, com tempo de exposição de 0 horas, são as amostras que não foram expostas ao método SODIS, ou seja, são a água bruta coletada na ETA, sem passar por nenhum tratamento. Estas, representam as condições microbiológicas iniciais da água, e servem para comparar a quantidade de microrganismos eliminados durante o processo do método SODIS. A concentração dos microrganismos, presentes nas amostras TO apresentam grande variabilidade por serem coletados em diferentes dias, podendo haver variações de vazão no ponto de coleta e também diferentes condições pluviométricas nos dias que antecedem a coleta. A partir das três repetições do experimento, obteve-se a média dos resultados microbiológicos em dias ensolarados (tabela 4).

Tabela 4: Média dos resultados microbiológicos em dias ensolarados.

\begin{tabular}{|l|l|l|l|l|}
\hline Média dos resultados dos experimentos \\
\hline Amostra & $\begin{array}{l}\text { Tempos de Exposição } \\
(\mathrm{h})\end{array}$ & $\begin{array}{l}\text { Colifrmes } \\
(\mathrm{NMP} / 100 \mathrm{ml})\end{array}$ & $\begin{array}{l}\text { E. } \\
(\mathrm{NMP} / 100 \mathrm{ml})\end{array}$ & $\begin{array}{l}\text { Coliformes } \\
(\mathrm{NMP} / 100 \mathrm{ml})\end{array}$ \\
\hline T0 & 0 & 335,67 & 2,40 & 52,17 \\
\hline T1 & 6 & 20,10 & 0,6 & 3,67 \\
\hline T2 & 7 & 5,23 & 0,6 & Ausente \\
\hline T3 & 8 & Ausente & Ausente & Ausente \\
\hline
\end{tabular}

Conforme dos dados apresentados na tabela 4, pode-se perceber que a carga microbiológica da água foi reduzindo proporcionalmente ao tempo de exposição à radiação solar. As análises realizadas na amostra bruta (TO), apresentaram a média de resultados de 335,67 NPM/100mL, 2,4 NPM/100mL e 52,17 NMP/100mL, em Coliformes Totais, E. coli e Coliformes Termotolerantes, respectivamente. Após submeter ao tratamento SODIS, em 8 horas de exposição, obteve-se a ausência de todos os microrganismos avaliados.

Mesmo que os Coliformes Termotolerantes, estejam ausentes em T2, observado na tabela 4, é apenas em T3 que os resultados atendem os padrões microbiológicos da Portaria no 2.914/11 do Ministério da Saúde, apresentando ausência de Coliformes Totais e também E. coli em $100 \mathrm{~mL}$ de amostra. A eficiência de remoção dos microrganismos conforme os tempos de exposição a energia solar, foi realizada com base na Equação (1), e seus resultados podem ser verificados na tabela 5. 
Tabela 5: Média da Eficiência de Inativação dos Microrganismos (\%) em dias Ensolarados.

\begin{tabular}{|l|l|l|l|l|}
\hline \multicolumn{6}{|l|}{ Eficiência de inativação dos microrganismos (\%) } \\
\hline Amostra & Tempo de Exposição (h) & Coliformes Totais & E. coli & Coliformes Termotolerantes \\
\hline T0 & 0 & 0 & 0 & 0 \\
\hline T1 & 6 & 86,03 & 66,67 & 83,33 \\
\hline T2 & 7 & 92,54 & 66,67 & 100 \\
\hline T3 & 8 & 100 & 100 & 100 \\
\hline
\end{tabular}

Em T0 na amostra de água bruta, a eficiência de inativação foi de $0 \%$, já que a amostra não foi submetida ao tratamento SODIS. Em T1, com 6 horas de exposição à energia solar, obteve-se os seguintes valores de inativação da carga microbiológica $86,03 \%$ para coliformes totais, $66,67 \%$ para E. coli e $83,33 \%$ para Coliformes Termotolerantes. Em T2 a eficiência foi superior apresentando os valores de 92,54\%, 66,67\% e 100\% de remoção de Coliformes Totais, E. coli e Coliformes Termotolerantes, respectivamente. Na amostra T3, com 8 horas de exposição, a eficiência média de remoção de todos os microrganismos analisados foi de 100\%. O estudo desenvolvido por Silva Filho (2015) no município de Pombal-PB, apresentou a redução de 99,9\% de Coliformes Totais e Termotolerantes em um período de $9 \mathrm{~h}$ de exposição à radiação solar, porém, tempos de exposição inferiores não foram analisados pelo autor.

Oliveira (2014), em estudo desenvolvido em Alagoa Nova-PB, apresentou dados de $100 \%$ de eficiência de inativação da carga microbiológica em amostras de água pelo método SODIS, em 4 horas de exposição à radiação solar. A maior rapidez de inativação deve-se ao fato da autora ter utilizado um Concentrador Solar no local aonde as garrafas PET ficaram expostas. As garrafas que não utilizaram Concentrador Solar, apresentaram valores inferiores de eficiência, sendo estes $99,81 \%$ para Coliformes Totais e 99,91\% para Coliformes Termolerantes, em 4 horas de exposição.

\section{Resultados em dias Nublados}

Nos dias nublados foram realizadas três baterias de ensaios em três diferentes dias que apresentavam predomínio de nuvens no céu, os ensaios em triplicata foram realizados afim de contrabalancear as variações climáticas existentes em diferentes dias. Os dias dos ensaios para condição climática nublada ocorreram nas datas de 20, 21 e 27 de fevereiro de 2018. Os resultados expressos em NMP de microrganismos por $100 \mathrm{~mL}$ de amostra de água, estão apresentados na tabela 6 .

Assim como nos dias ensolarados, as amostras T0, com tempo de exposição de 0 horas, são as amostras que não foram expostas ao método SODIS, ou seja, a água bruta coletada na ETA, sem passar por nenhum tratamento, representando as condições microbiológicas iniciais da água. A concentração dos microrganismos, presentes nas amostras T0 apresentam grande variabilidade devido às variações de vazão a montante do ponto de coleta e também das condições climáticas nos dias que antecedem a coleta. Por meio da triplicata do experimento, obteve-se a média dos resultados microbiológicos em dias nublados (tabela 7).

A carga microbiológica da água foi reduzindo proporcionalmente ao tempo de exposição à energia solar. Os resultados das análises feitas na amostra de água bruta (TO), apresentaram como média 171,00 NPM/100mL, 3,03 NPM/100mL e 123,83 NMP/100mL, em Coliformes Totais, E. coli e Coliformes 
Termotolerantes, respectivamente. Ao submeter ao tratamento SODIS, em 8 horas de exposição (T2), obteve-se uma redução da carga microbiológica para 14,33 NPM/100mL, 0,6 NPM/100mL e 7,67 NMP/100mL. Em T2 com 29 horas de exposição, a carga de E. coli e de Coliformes Termotolerantes já se encontravam ausentes, e os Coliformes Totais foram reduzidos para 5,00 NPM/100mL. Em um tempo de exposição de 32 horas (T3), todos os parâmetros microbiológicos avaliados apresentaram-se ausentes.

Tabela 6: NMP em $100 \mathrm{~mL}$ do experimento SODIS em dias Nublados.

\begin{tabular}{|c|c|c|c|c|c|}
\hline Amostra & Data & Tempo de Exposição (h) & Coliformes Totais & Coliformes Termotolerantes & E. coli \\
\hline TO & \multirow{4}{*}{$20 /$ fev } & 0 & 350 & 4,5 & 3,6 \\
\hline T1 & & 8 & 11 & Ausente & 1,8 \\
\hline T2 & & 29 & Ausente & Ausente & Ausente \\
\hline T3 & & 32 & Ausente & Ausente & Ausente \\
\hline TO & \multirow{4}{*}{$21 / \mathrm{fev}$} & 0 & 33 & 27 & 1,8 \\
\hline T1 & & 8 & 17 & 2 & Ausente \\
\hline T2 & & 29 & 11 & Ausente & Ausente \\
\hline T3 & & 32 & Ausente & Ausente & Ausente \\
\hline TO & \multirow{4}{*}{$27 / \mathrm{fev}$} & 0 & 130 & 340 & 3,7 \\
\hline T1 & & 8 & 15 & 21 & Ausente \\
\hline 2 & & 29 & 4 & Ausente & Ausente \\
\hline T3 & & 32 & Ausente & Ausente & Ausente \\
\hline
\end{tabular}

Tabela 7: Média dos resultados microbiológicos em dias Nublados.

\begin{tabular}{|c|c|c|c|c|c|}
\hline \multicolumn{6}{|c|}{ Média dos resultados dos experimentos } \\
\hline Amostra & $\begin{array}{l}\text { Tempos de Exposição } \\
\text { (h) }\end{array}$ & $\begin{array}{ll}\text { Colifrmes } & \text { Totais } \\
\text { (NMP/100ml) } & \\
\end{array}$ & $\begin{array}{ll}\text { E. } & \text { coli } \\
\text { (NMP/100ml) }\end{array}$ & $\begin{array}{l}\text { Coliformes } \\
\text { (NMP/100ml) }\end{array}$ & Termotolerantes \\
\hline T0 & 0 & 171,00 & 3,03 & 123,83 & \\
\hline $\mathrm{T} 1$ & 8 & 14,33 & 0,6 & 7,67 & \\
\hline $\mathrm{T} 2$ & 29 & 5,00 & Ausente & Ausente & \\
\hline T3 & 32 & Ausente & Ausente & Ausente & \\
\hline
\end{tabular}

Mesmo que em T2 os Coliformes Termotolerantes e a E. coli, já estejam ausentes, é apenas em T3 que os resultados atendem os padrões microbiológicos da Portaria no 2.914/11 do Ministério da Saúde, apresentando ausência de Coliformes Totais e E. coli em $100 \mathrm{~mL}$ de amostra. Pode-se perceber que em dias nublados para que todos os microrganismos analisados ficassem ausentes nas amostras de água, o tempo de exposição à radiação solar precisou ser de 32 horas, sendo este superior aos tempos em dias ensolarados, em que foi necessário apenas 8 horas de exposição. Esta diferença de tempo é relacionada com o fato das condições climáticas e das diferentes épocas anuais, as quais interferem diretamente na eficiência do método. Borde (2016) também afirma que em algumas condições climáticas, tempos de exposição de até dois dias são recomendados para os níveis de radiação solar para desinfetar adequadamente a água, não recomendando o uso de SODIS em dias de fortes chuvas.

Tabela 8: Média da Eficiência de Inativação dos Microrganismos (\%) em dias Nublados.

\begin{tabular}{|l|l|l|l|l|}
\hline Eficiência de inativação dos microrganismos (\%) \\
\hline Amostra & Tempo de Exposição (h) & Coliformes Totais & E. coli & Coliformes Termotolerantes \\
\hline T0 & 0 & 0 & 0 & 0 \\
\hline T1 & 8 & 77,93 & 83,33 & 95,47 \\
\hline T2 & 29 & 87,86 & 100 & 100 \\
\hline T3 & 32 & 100 & 100 & 100 \\
\hline
\end{tabular}

A tabela 8 apresenta a eficiência de inativação dos microrganismos conforme os tempos de exposição à radiação solar, sendo que os cálculos foram baseados na Equação (1). Na amostra de água bruta (T0), a 
eficiência de inativação foi de 0\%, pois a amostra não foi submetida ao tratamento de Desinfecção Solar SODIS. Já em T1, com 8 horas de exposição à energia solar, a eficiência de inativação da carga microbiológica foi de $77,93 \%$ para coliformes totais, $83,33 \%$ para E. coli e $95,47 \%$ para Coliformes Termotolerantes. Em T2 a eficiência foi superior apresentando os valores de 87,86\%, 100\% e 100\% de inativação de Coliformes Totais, E. coli e Coliformes Termotolerantes, respectivamente. Na amostra T3, com 32 horas de exposição, a eficiência média de inativação de todos os microrganismos analisados foi de $100 \%$. Os resultados obtidos estão de acordo com o que foi apresentado por Sommer (1997). Segundo o autor, com tempo nublado, menos energia de radiação está disponível, sendo assim, durante estes dias a intensidade da radiação UV-A é reduzida a um terço da intensidade registrada durante um dia sem nuvens, portanto, as garrafas com água do SODIS devem ser expostas durante dois dias consecutivos para alcançarem a dose de radiação exigida e assegurar a inativação completa dos agentes patogênicos.

\section{CONCLUSÕES}

Através dos resultados obtidos por este estudo, pode-se concluir que houve uma alta eficiência do método SODIS no que diz respeito a desinfecção da água para consumo humano no município de Pelotas RS. Para que ocorra a completa inativação de patógenos por meio do método SODIS, o tempo de exposição necessário varia de acordo com certos parâmetros, incluindo a turbidez da água e a presença ou ausência de nuvens no céu. Sendo assim, os valores das cargas de Coliformes Totais, Escherichia coli e Coliformes Termotolerantes, expressos em NMP em $100 \mathrm{~mL}$ de amostra, foram reduzindo proporcionalmente ao tempo de exposição à radiação solar. Os microrganismos apresentaram-se totalmente ausentes em 8 horas de tratamento do método SODIS em dias ensolarados e em 32 horas em dias nublados.

No município de pelotas por meio do método SODIS, em dias ensolarados foi possível alcançar os parâmetros microbiológicos estabelecidos pela Portaria 2.914 do Ministério da Saúde, no que concerne as análises microbiológicas, em 8 horas de exposição da amostra de água à energia solar, já para dias nublados isso ocorreu em 32 horas de exposição.

\section{REFERÊNCIAS}

ACRA, A.; RAFFOUL, Z.; KARAHAGOPIAN, Y.. Solar Disinfection of Drinking Water and Oral Rehydration Solutions: guidelines for household application in developing countries. Beirute: UNICEF, 1984.

APHA; AWWA; WF. Standard Methods for the Examination of Water and Wastewater. $22 \mathrm{ed}$. Washington: American Public Health Association, 2017.

BORDE, P.; ELMUSHARAF, K.; McGUIGAN, K.; KEOGH, M. B.. Community challenges when using large plastic bottles for Solar Energy Disinfection of Water (SODIS). BMC Public Health, v.16, n.931, 2016.

BRASIL. Portaria MS № 2914. Brasília: Ministério da Saúde. Brasília, 2011.
BRASIL. Ministério da Saúde. Secretaria de Vigilância em Saúde. Diretriz Nacional do Plano de Amostragem da Vigilância da Qualidade da Água para Consumo Humano. Brasília: Ministério da Saúde, 2016.

BRASIL. Relatório Nacional Voluntário sobre os Objetivos de Desenvolvimento Sustentável. Brasília: Secretaria de Governo da Presidência da República/Ministério do Planejamento, Desenvolvimento e Gestão, 2017.

EAWAG; SANDEC. Desinfecção Solar da Água: Guia de Aplicação SODIS. Switzerland: SKAT, 2002.

EAWAG; SANDEC. SODIS Manual: Guidance on solar water disinfection. Switzerland: Eawag, 2016.

EMBRAPA. Dados Climáticos: Boletins Mensais. 2018. 
SILVA FILHO, J. A.; OLIVEIRA, A. M. B. M.; MARTINS, W. A.; BEZERRA, A. M. S.; COELHO, L. F. O.. Eficácia e viabilidade da técnica SODIS utilizando a água do Rio Piranhas destinado ao consumo humano. INTESA: Informativo Técnico do Semiárido, Pombal, v.9, n.2, p.16-20, 2015.

GRABOW, W.. Waterborne diseases: Update on water quality assessment and control. Water S.A. Pretória, v.22, n.2, p.193-202, 1996

IBGE. Instituto Brasileiro de Geografia e Estatística. Estimativas da População Residente para os Municípios e para as Unidades da Federação Brasileiros com data de Referência em 10 de julho de 2017. 2018.

IBGE, Instituto Brasileiro de Geografia e Estatística. Censo Demográfico 2010. Universo - Características da População e dos domicílios. 2010.

LIBÂNO, M.. Fundamentos de Qualidade e Tratamento da Água. Desinfecção. 4 ed. Campinas: Átomo, 2016.

OLIVEIRA, S. C.. Avaliação da Eficiência do Método SODIS com e sem o uso de Concentrador Solar para Desinfecção de Água da Cisterna Localizada na Zona Rural de Alagoa Nova - PB. Monografia (Bacharel em Engenharia Sanitária e Ambiental) - Universidade Estadual da Paraíba, Campina Grande, 2014

ONU, Organização das Nações Unidas. Transforming our World: The 2030 Agenda for Sustainable Development. 2018.

SOMMER, B.; SOLARTE, Y.; MARIÑO, A.; SALAS, M. L.. SODIS: An Emerging Water Treatment Process. Journal of Water
Suply: Research and Technology - Aqua, Zurich, v.46, n.3, p.127-137, 1997.

SOUZA, L. C.. Águas e sua Proteção: Meio Ambiente, Poluição das Águas, Responsabilidade Civil, Evolução Legislativa, Inconstitucionalidade, Política de Recursos Hídricos. Curitiba: Juruá, 2005.

TELLES, D. D.; COSTA, R. H. P. G.. Reuso da água: Conceitos, Teorias e Práticas. 2 ed. São Paulo: Blucher, 2007.

UN-WATER. Water and sanitation interlinkages across the 2030 Agenda for Sustainable Development. Geneva, 2016.

UNEP. United Nations Environment Programme. Towards a Worldwide Assessment of Freshwater Quality: A UN-Water Analytical Brief. ONU-Water, 2016.

UNESCO. International Initiative on Water Quality: promoting scientific research, knowledge sharing, effective technology and policy approaches to improve water quality for sustainable development. Paris: United Nations Educational, Scientific and Cultural Organization, 2015.

WHO. Guidelines for Drinking-Water Quality. Surveillance. 4 ed. Geneva: WHO, 2011.

WHO; UNICEF. Progress on Drinking Water, Sanitation and Hygiene: 2017. Geneva: WHO, 2017.

WREGE, S. M.; STEINMETZ, S.; REISSER JUNIOR, C.; ALMEIDA, I. R.. Atlas Climático da Região Sul do Brasil: Estados do Paraná, Santa Catarina e Rio Grande do Sul. 2 ed. Brasília: Embrapa, 2012.

A CBPC - Companhia Brasileira de Produção Científica (CNPJ: 11.221.422/0001-03) detém os direitos materiais desta publicação. Os direitos referem-se à publicação do trabalho em qualquer parte do mundo, incluindo os direitos às renovações, expansões e disseminações da contribuição, bem como outros direitos subsidiários. Todos os trabalhos publicados eletronicamente poderão posteriormente ser publicados em coletâneas impressas sob coordenação da Sustenere Publishing, da Companhia Brasileira de Produção Científica e seus parceiros autorizados. Os (as) autores (as) preservam os direitos autorais, mas não têm permissão para a publicação da contribuição em outro meio, impresso ou digital, em português ou em tradução. 